\title{
Leaf Area Assessment By Image Analysis
}

\author{
Mehmet Can ${ }^{a}$, Osman Gursoy ${ }^{b}$, Betul Akcesme ${ }^{\mathrm{c}}$, Faruk Berat Akcesme ${ }^{\mathrm{d}}$ \\ a, Mathematics, International University of Sarajevo, 71210, mcan@ius.edu.ba \\ bComputer Science and Engineering, International University of Sarajevo, 71210, ogursoy@ius.edu.ba \\ 'Genetics and Bioengineering, Internantional University of Sarajevo, 71210 bcicek@ius.edu.ba \\ ${ }^{\mathrm{d} G e n e t i c s}$ and Bioengineering, International University of Sarajevo, 71210 fakcesme@ius.edu.ba
}

\begin{abstract}
A measurement of leaf area is apparently simple and fundamental. Various methods are available to measure leaf area. Available methods are time consuming, humdrum and laborious. Less expensive methods involving image processing based on video camera images and computer programs for analysis of these images have been alternative for all other techniques for leaf area assessment. In this paper we introduce a computer program that can calculate leaf area meter based on the pixel count in very short time and highly accurate by image processing. This program provides very fast, inexpensive and highly accurate measurement.
\end{abstract}

Keywords—image processing, leaf area measurement. 


\section{INTRODUCTION}

Measuring the leaf area of plants is an interest of many scientific disciplines. Determining the distribution and changes of leaf area is significant for assessing growth, physiology analysis and strength of vegetation on the planet. It is very important as a parameter in land-surface processes and climate models. In addition, leaf traits play a particularly important role in carbon assimilation, water relations and energy balance. (D. D. Ackerly et al. , 2002) The leaf area effect various processes directly or indirectly such as photosynthesis, respiration, transcription and rain interception which are all play crucial role in biosphere and atmosphere relations. (Guo \& Sun, 2001) A measurement of leaf area is apparently simple and fundamental. However, it is crucial for providing framework for future research in areas like agronomy, ecology, carbon cycle research, plant pathology; host plant resistant (Jansky et al. 1999) , pesticide activity (Gonzalez et al. 1992, Hoy and Hall 1993 , Wheler and Isman 2001 ) and plant insect interaction (Peterson et al. 1993, 7 Hammond et al. 2000). Moreover, leaf area is an important parameter for phenotypic growth analysis of mutant screens.

Various methods are available to measure leaf area. Some of these methods have disadvantages; leaf area meters are expensive and measuring leaf area by hand with a sampling grid is time consuming. (O’NEAL, M, 2002) Mathematical models involving linear measurements are another alternative way to measure leaf area which is relatively accurate. (Blanco, F. F, 2003)

General strategy of measuring the leaf areas is one-side surface area measurement of all individuals' leaves. This is accepted as a powerful strategy to diagnose plant productivity. (D. D. Ackerly et al., 2002) Current applications require each plant leaf to be manually slipped through a dedicating measuring machine. (Wubs et al, 2009) This process is time consuming, humdrum and laborious. Because of the difficulties, leaf area measurement during the plant growth generally not possible and they have been simulated empirically in plant growth analysis. (Heuvelink, 1998)

Less expensive methods involving image processing based on video camera images and computer programs for analysis of these images have been alternative for all other techniques for leaf area assessment. (Hargrove \& Crossley, 1988; 14 Hagerup et al, 1990). These methods provide automatic calculation of leaf areas, and of areas lost to herbivores or disease, depending on the computer programs used.

Image processing is promising to overcome these problems but there is still long way for automatic interpretation of plant images. (Yu Song,) Although estimating plant characteristics such as leaf area stem length or fruit size and color challenging with image analysis, image analysis could contribute greatly to increased quality and yield of plant product due to its cheaper and practical usage.

\section{MATERIALS AND METHODS}

Sample of 15 leaves were collected from representative Platanus $x$ hispanica trees. Leaf area was measured using the Li-3000C Portable Area Meter (data are not shown). Meanwhile, the all leaves were photographed on a standard A4 size paper which is indented to be used as a reference for real metric conversion. All images are firstly processed by using Adobe Photoshop CS5 in order to be recorded and kept for comparing with the designed online leaf assessment tool (OLAT).

OLAT is developed with PHP, a general-purpose server-side scripting language and is being widely used. PHP has also provided a base to analyze images.

OLAT firstly resizes the given image to $400 \times 400$ pixels with keeping its aspect ratio. Since images have the reference of A4 paper size as a background, reducing the image size does not affect the results and helps to reduce computational time.

Secondly, OLAT converts given image to gray scale with applying the following threshold:

\begin{tabular}{|c|c|c|c|}
\hline $\begin{array}{c}\text { Leaf Area } \\
\text { Measurement by } \\
\text { developed } \\
\text { program }\end{array}$ & $\begin{array}{c}\text { Leaf Area } \\
\text { Measurement by } \\
\text { Adobe Photoshop } \\
\text { CS5 }\end{array}$ & $\begin{array}{c}\text { Absolute } \\
\text { Errors }\end{array}$ & $\begin{array}{c}\text { Errors in } \\
\text { percentage }\end{array}$ \\
\hline $91,65 \mathrm{~cm}^{2}$ & $91,98 \mathrm{~cm}^{2}$ & $0,33 \mathrm{~cm}^{2}$ & 0,36 \\
\hline $148,72 \mathrm{~cm}^{2}$ & $147,99 \mathrm{~cm}^{2}$ & $0,73 \mathrm{~cm}^{2}$ & 0,49 \\
\hline $118,41 \mathrm{~cm}^{2}$ & $117,86 \mathrm{~cm}^{2}$ & $0,55 \mathrm{~cm}^{2}$ & 0,47 \\
\hline $228,14 \mathrm{~cm}^{2}$ & $226,45 \mathrm{~cm}^{2}$ & $1,69 \mathrm{~cm}^{2}$ & 0,74 \\
\hline $103,08 \mathrm{~cm}^{2}$ & $102,77 \mathrm{~cm}^{2}$ & $0,31 \mathrm{~cm}^{2}$ & 0,30 \\
\hline $136,05 \mathrm{~cm}^{2}$ & $136,66 \mathrm{~cm}^{2}$ & $0,61 \mathrm{~cm}^{2}$ & 0,45 \\
\hline $117,9 \mathrm{~cm}^{2}$ & $119,58 \mathrm{~cm}^{2}$ & $1,68 \mathrm{~cm}^{2}$ & 1,41 \\
\hline $168,04 \mathrm{~cm}^{2}$ & $172,51 \mathrm{~cm}^{2}$ & $4,47 \mathrm{~cm}^{2}$ & 2,59 \\
\hline $129,17 \mathrm{~cm}^{2}$ & $130,67 \mathrm{~cm}^{2}$ & $1,50 \mathrm{~cm}^{2}$ & 1,15 \\
\hline $143,73 \mathrm{~cm}^{2}$ & $143,35 \mathrm{~cm}^{2}$ & $0,38 \mathrm{~cm}^{2}$ & 0,27 \\
\hline $195,09 \mathrm{~cm}^{2}$ & $197,35 \mathrm{~cm}^{2}$ & $2,26 \mathrm{~cm}^{2}$ & 1,14 \\
\hline $120,53 \mathrm{~cm}^{2}$ & $120,48 \mathrm{~cm}^{2}$ & $0,05 \mathrm{~cm}^{2}$ & 0,04 \\
\hline $72,14 \mathrm{~cm}^{2}$ & $71,00 \mathrm{~cm}^{2}$ & $1,14 \mathrm{~cm}^{2}$ & 1,60 \\
\hline $73,04 \mathrm{~cm}^{2}$ & $73,23 \mathrm{~cm}^{2}$ & $0,19 \mathrm{~cm}^{2}$ & 0,26 \\
\hline $69,32 \mathrm{~cm}^{2}$ & $69,34 \mathrm{~cm}^{2}$ & $0,02 \mathrm{~cm}^{2}$ & 0,02 \\
\hline Averages: & $128,08 \mathrm{~cm}^{2}$ & $1,06 \mathrm{~cm}^{2}$ & 1,06 \\
\hline
\end{tabular}

Table 1Final Results from OLAT and Measured Values in Photoshop

IF greypixelvalue $>=76$ THEN
greypixelvalue $=255$
ELSE $\quad \begin{aligned} & \text { greypixelvalue }=0 \\ & \text { END IF }\end{aligned}$


Thirdly, OLAT detects the background A4 paper position and crops the image accordingly. Detecting the A4 position in the image is crucial because, real metric reference of the image size depends on this part of the image.

In order to detect the background paper in the image, OLAT checks the all sides of the image from top to bottom and left to right. Meanwhile it detects the consecutive white pixels which dominate to corresponding side of the image with a percentage of 70 . After cropping, total number of the pixel for $1 \mathrm{~cm}^{2}$ in the image is calculated as in the following:

\section{OneCm2= (imagewidth*imageheight)/(27.9*21)}

Finally, OLAT counts all black pixels and calculates the final real metric result as in the following:

\section{TotalNumberofBlackPixels / OneCm2}

\section{RESULT AND DISCUSSION}

Since the Adobe Photoshop CS5 and manually slipped through a dedicating measuring machine is time consuming and expensive the designed program provide very fast and accurate measurement. The measurements that are obtained from the program were compared with the Adobe Photoshop CS5 measurement. These comparisons reveal that developed program is able to count the pixels and measure the surface of area in a high degree of precision as in shown Table 1.

Especially for the laboratories that are not specified for the plant growth analysis and measure leaves often, the developed online tool for area assessment is very useful. In the developed program there are very little restrictions. The user needs to take leaf image with constant background which is simple white A4 blank paper. The photographs must be uploaded in jpeg format. User does not need to put slide ruler beside the target area in order to convert to pixels to the meter scale. There is no need to download any program; program can work online with free access.

\section{ACKNOWLEDGMENT}

Thanks to Prof. Can for his encouragement and all helps.

\section{REFERENCES}

Ackerly, D. D., C. A. Knight, S. B. Weiss, K. Barton and K. P. Starmer.( 2002). Leaf size, specific leaf area and microhabitat distribution of chaparral woody plants: contrasting patterns in species level and community level analyses. Oecologia 130: 449-457. DOI $10.1007 / \mathrm{s} 004420100805$

Blanco, F. F.; Folegatti, M.V. (2003) A new method for estimating the leaf area index of cucumber and tomato plants. Horticultura Brasileira, Brasília, v. 21, n. 4, p. 666-669.

Caldas,L., Bravo, C., Piccolo,H., faria, C., (1992) Measurement of leaf area with a hand scanner linked to a microcomputer. R. Bras. Fisiol. Veg. 4 (1):17-20
Gonzalez, A. G., I. A. Jimenez, A. G. Ravelo, X. Belles, and M. D. Piulachs. (1992). Antifeedent activity of dihydroB-agarofuran sesquiterpenes from Celastraceae against Spodoptera littoralis. Biochem. Syst. Ecol. 20: 311-315

GUO, D.P.; SUN, Y.Z. (2001) Estimation of leaf area of stem lettuce (Lactuca sativa var angustana) from linear measurements. Indian Journal of Agricultural Sciences, v.71, p.483-486,.

Hagerup, M.; Sondergard, I. \& Nielsen. J. K. (1990)Measurements of areas consumed from leaf discs by chewing phytophagous insects: Description of a new method involving image processing.Entomologia Experimentalis et Applicata., 57:105- 113

Hammond, R. B., L. G. Higley, L. P. Pedigo, L. Bledsoe, S. M. Spomer, and T. A. Degooyer. (2000). Simulated insect defoliation on soybean: inßuence of row width. J. Econ. Entomol. 93: 1429 -1436.

Hargrovec, W.W. \& Crossley Jr., D.A. 1-(1988.)Video digitizer for the rapid measurement of leaf area lost to herbivorous insects. Annals of the Entomological Society of America, 81:593-598,

Heuvelink, E.: (1998) Evaluation of a dynamic simulation model for tomato crop growth and development. Annals of Botany 83, 413-422

Hoy, C. W., and F. R. Hall. (1993). Feeding behavior of Plutella xylostella and Leptinotarsa decemlineata on leaves treated with Bacillus thuringiensis and esfenvalerate. Pestic. Sci. 38: 335-340

Jansky, S., S. Austin-Phillips, and C. McCathy. 1999. Colorado potato beetle resistance in somatic hybrids of diploid interspecific Solanum clones. Hortic. Sci. 34: 922-927.

O’neal, M., Landis,D., and Isaacs,R, (2002) An Inexpensive, Accurate Method for Measuring Leaf Area and Defoliation Through Digital Image Analysis J. Econ. Entomol. 95(6): 1190-1194

Peterson, R.K.D., S. D. Danielson, and L. G. Higley. (1993). Yield responses of alfalfa to simulated alfalfa -weevil injury and development of economic injury levels. Agron. J. 85: 595- 601.

Song,Y., Chris, A. G., Polder,G., Gerie W.A.M. van der Heijden. Non-destructive Automatic Leaf Area Measurements by Combining Stereo and Time-of-Flight Images. Under review.

Wheeler, D. A., and M. B. Isman. (2001). Antifeedant and toxic activity of Trichilia americana extract against the larvae of Spodoptera litura. Entomol. Exp. Appl. 98: 9 -16.

Wubs, A.M., Ma, Y., Hemerik, L., Heuvelink, E. (2009) : Fruit set and yield patterns in six capsicum cultivars. HortScience 44, 1296130 